\title{
Sleep-related problems in the US working population: prevalence and association with shiftwork status
}

\author{
Lee C Yong, Jia Li, Geoffrey M Calvert
}

Division of Surveillance, Hazard Evaluations and Field Studies, National Institute for Occupational Safety and Health, Centers for Disease Control and Prevention, Cincinnati, Ohio, USA

\section{Correspondence to} Dr Geoffrey M Calvert, National Institute for Occupational Safety and Health, 1090 Tusculum Avenue, R-17, Cincinnati, OH 45226, USA; jac6@cdc.gov

Received 11 February 2016 Revised 8 August 2016 Accepted 20 August 2016
CrossMark

To cite: Yong LC, Li J, Calvert GM. Occup Environ Med 2017;74:93-104.

\section{ABSTRACT}

Objective To estimate the prevalence of a comprehensive set of self-reported sleep problems by job characteristics, including shiftwork status, among a representative sample of US workers.

Methods Data for 6338 workers aged $\geq 18$ years were obtained from the National Health and Nutrition

Examination Survey. Short sleep duration was defined as $<7$ hours per weekday/workday. Sleep quality was categorised as good, moderate and poor based on the frequency of 6 sleep-related symptoms. A sleep-related activities of daily living (ADL) score $\geq 2$ was defined as impaired. Insomnia was defined as having poor sleep quality and impaired ADL. Shiftwork status was categorised as daytime, night, evening, rotating or another schedule. Prevalence rates were calculated and multivariate logistic regression analyses were used.

Results The prevalence of short sleep duration (37.6\% overall) was highest among night shift workers (61.8\%; $p<0.001)$. The prevalence of poor sleep quality was $19.2 \%$ among all workers, with the highest prevalence among night shift workers $(30.7 \%, p=0.004)$. The prevalence of impaired ADL score ( $24.8 \%$ overall) and insomnia ( $8.8 \%$ overall) was also highest for night shift workers $(36.2 \%, p=0.001$ and $18.5 \%, p=0.013$, respectively). In multivariate analysis, night shift workers had the highest likelihood of these sleep problems.

Conclusions Self-reported short sleep duration, poor sleep quality, impaired ADL score and insomnia are common among US workers especially among night shift workers. Although these findings should be confirmed with objective sleep measures, they support the need for intervention programmes to improve sleep quantity and quality among night shift workers.

\section{INTRODUCTION}

Although sleep is essential to health and wellbeing, an estimated 50-70 million Americans suffer from a sleep disorder. ${ }^{1}$ Short sleep duration ( $<7$ hours/day) has been shown in some studies to be associated with many chronic health problems, including immune dysfunction, obesity, diabetes, hypertension, cardiovascular disease and all-cause mortality risk. ${ }^{2-4}$ Sleepiness and fatigue, the consequences of short sleep duration, have been linked to undesirable job impacts, including productivity loss ${ }^{5}$ and adverse safety outcomes. ${ }^{67}$ Sleep deficiency is thus an important public

\section{What this paper adds}

- Little is known about the prevalence of sleeprelated problems in the US working population.

- This is the first study to use a nationally representative sample of the US working population to examine the role of shiftwork on sleep quality, sleep-related activities of daily living (ADL) and insomnia.

- Short sleep duration, poor sleep quality, impaired sleep-related ADL and insomnia were common among US workers, especially among night shift workers.

- Work-based programmes and policies should be adopted to improve the quantity and quality of sleep among workers.

health problem affecting a large proportion of the US population, and costs billions of dollars annually. ${ }^{8}$

Workers with irregular work schedules and those not working the 09:00 to 17:00 time frame are increasingly needed to meet the demands of globalisation and a 24-hour society. According to the Sleep in America Poll, 25\% of the workers in the USA reported that their current work schedule does not permit sufficient sleep. ${ }^{9}$ Shift workers are known to have more sleep-related problems than the general population, including difficulty falling asleep, not getting enough sleep and sleepiness on waking. ${ }^{10} 11$

To date, little is known about the prevalence of sleep-related problems in the US working population as the majority of studies are limited to selected occupational groups or geographic regions ${ }^{12} 13$ with limited generalisability. Furthermore, most of the studies focused on a few specific problems, such as short sleep duration ${ }^{14} 15$ or insomnia. ${ }^{5}$ Therefore, using nationally representative data from National Health and Nutrition Examination Survey (NHANES), we (1) estimated the prevalence of a comprehensive set of self-reported sleep problems by job characteristics, including shiftwork status, selected sociodemographic characteristics, and health and lifestyle factors among US workers; and (2) performed an in-depth examination of the association between these sleep problems and shiftwork status, adjusted for sociodemographic characteristics and other potential confounders. 


\section{METHODS}

\section{Study design and population}

Data from NHANES, a continuous series of cross-sectional surveys conducted by the National Center of Health Statistics (NCHS) of the Centers for Disease Control and Prevention, were used. A detailed description of the recruitment, design and surveys is available online (http://www.cdc.gov/nchs/nhanes/ about_nhanes.htm). Briefly, data were collected in 2-year cycles using a stratified multistage probability design to ensure a nationally representative sample of the non-institutionalised US civilian population. Participants were interviewed in their homes, followed by an invitation to undergo various examinations, provide a blood sample and complete additional questionnaires.

The current analysis was limited to the NHANES 2005-2006 and 2007-2008 cycles only. Detailed data on sleep habits and sleep-related problems were not collected before 2005 or after 2008. The unweighted response rates for the two cycles were $78.4 \%$ and $75.4 \%$, respectively. Since the exposure of interest was shiftwork, we excluded participants who were unemployed in the past week. This left an analytical sample of 6338 adults aged $\geq 18$ years. All participants gave written informed consent. The NHANES study protocol was approved by the NCHS Research Ethics Review Board.

\section{Sleep-related variables}

Study participants completed a sleep questionnaire that included items from previously validated instruments. ${ }^{16}$

\section{Sleep duration}

Sleep duration was determined from the question, 'How much sleep do you usually get at night on weekdays or workdays?' with responses recorded in whole hours and $\geq 12$ hours coded as ' 12 '. This question did not have a specific time component (eg, in the last week or month). Based on the National Sleep Foundation recommendation that adults should sleep 7-9 hours per night, ${ }^{17}$ two categories of sleep duration were created: $<7$ (ie, short sleep duration) and $\geq 7$ hours per weekday or workday.

\section{Sleep disorders}

Physician-diagnosed sleep disorders were first identified by a 'yes' response to the question, 'Have you ever been told by a doctor or other health professional that you have a sleep disorder?'. This was followed by questions to ascertain the specific type of diagnosed disorder: sleep apnoea; insomnia; restless leg syndrome; or 'other'. Self-reported sleep latency or time to sleep was categorised as $<30$ and $\geq 30 \mathrm{~min}$ based on the question, 'How long does it usually take you to fall asleep at bedtime?' (ie, without a time component). Frequent use of sleeping pills was defined as taking sleeping pills or other medication to help sleep five or more times in the preceding month.

\section{Sleep quality}

Self-reported trouble sleeping and ever having told a physician about trouble sleeping were assessed. Ever telling a physician about trouble sleeping was defined as answering 'yes' to 'Have you ever told a doctor or other health professional that you have trouble sleeping?'. Self-reported sleep symptoms in the past month was assessed by asking about the following six sleep symptoms: (1) trouble falling asleep; (2) waking up during the night and having trouble getting back to sleep; (3) waking up too early in the morning and being unable to get back to sleep;
(4) feeling unrested during the day, no matter how many hours of sleep were obtained; (5) feeling excessively or overly sleepy during the day and (6) not getting enough sleep. Each selfreported sleep symptom was considered frequent if the response was five or more times a month. We also created a sleep quality index by combining the frequency of self-reported sleep symptoms. ${ }^{18}$ Participants were categorised as having 'poor' sleep quality if the response to any of the six self-reported sleep symptoms was 16-30 times a month; else as having 'moderate' sleep quality if at least one response was 5-15 times a month; and all other participants were defined as having 'good' sleep quality.

\section{Sleep-related activities of daily living impairment}

Participants also completed a general productivity subscale of the Functional Outcomes of Sleep Questionnaire. ${ }^{19}$ The following eight items assessed the difficulty in performing certain activities of daily living (ADL) generally (ie, without a time component) due to excessive sleepiness: (1) concentrating on things, (2) remembering things, (3) eating or finishing a meal, (4) working on a hobby, (5) getting things done because too sleepy to drive or take public transportation, (6) taking care of financial affairs and doing paperwork (eg, paying bills), (7) performing paid or volunteer work and (8) maintaining a telephone conversation. Responses to each item were assigned a score: $0=$ no difficulty, $1=$ a little difficulty, $2=$ moderate difficulty and $3=$ severe difficulty (all other responses, including 'do not do this activity', were set to missing). The scores for the completed eight items were summed and participants were dichotomised based on the sample mean of $2 .^{20}$ A score $\geq 2$ suggests a greater amount of ADL impairment from sleep compared to those with a score $<2$.

\section{Insomnia}

Insomnia was loosely based on the definitions and criteria of the American Psychiatric Association (APA). ${ }^{21}$ Participants were categorised as having insomnia if they met these two conditions: (1) had poor sleep quality as defined above and (2) an ADL score suggesting impaired function (ie, ADL score $\geq 2$ ).

\section{Job exposures/characteristics}

Shiftwork status was determined by the question: 'Which best describes the hours you usually work?'. The response options were (1) regular daytime schedule ('work anytime between 06:00 and 18:00'), (2) regular evening shift ('work anytime between 14:00 and midnight'), (3) regular night shift ('work anytime between 17:00 and 08:00'), (4) rotating shift ('a work shift that changes periodically from days to evenings or nights') or (5) another schedule ('a split shift consisting of two distinct work periods each day, an irregular schedule arranged by the employer, or any other schedule'). We also assessed the effect of other job-related characteristics on sleep: duration of current main job ( $<10$ vs $\geq 10$ years), hours worked in all jobs in the preceding week ( $<48$ vs $\geq 48$ hours) and the occupation category for the main job (three categories: service, farm/blue collar and white collar).

\section{Covariates}

Several self-reported potential confounders were assessed: age, gender, race/ethnicity, marital status and education level. Socioeconomic status was assessed by the poverty income ratio (PIR), which was calculated as the ratio of self-reported family income to the poverty threshold level according to US Census Bureau poverty guidelines. $^{22}$ PIR was categorised as $<1$ (below 
the poverty threshold), 1 to $<3$ and $\geq 3$ (representing family income three or more times the poverty threshold). The health-related potential confounders included self-rated general health status dichotomised into two groups: excellent, very good or good health versus fair or poor health. Health insurance status was dichotomised as covered by any type of health insurance versus not insured. Prescription medication use was also dichotomised (yes vs no).

During the examination, weight and height were measured. Body mass index was calculated using these measurements and categorised as $<25.0$ (underweight/normal weight), 25.0-29.9 (overweight) and $\geq 30.0$ (obese). Current smoking status was assessed using serum cotinine; those with levels $>10 \mathrm{ng} / \mathrm{mL}$ were considered smokers and those with levels $\leq 10 \mathrm{ng} / \mathrm{mL}$ were considered non-smokers. Data were also collected on selfreported use of two substances that may affect sleep: alcohol and caffeine. Average daily caffeine intake (in $\mathrm{mg}$ ) was calculated from fluid (coffee, tea and soda) and food sources (chocolate) reported in two 24-hour dietary recalls, and categorised into quartiles based on intake distribution.

Depression was assessed using a validated questionnaire. ${ }^{23}$ Participants were asked about nine symptoms over the previous 2-week period (ie, little interest in doing things; feeling down, depressed or hopeless; trouble sleeping or sleeping too much; feeling tired or having little energy; poor appetite or overeating; feeling bad about yourself; trouble concentrating on things; moving or speaking slowly or too fast; and thinking it is preferable to be dead). The frequency of each symptom was assigned a score: $0=$ not at all, $1=$ several days, $2=$ more than half the days and $3=$ nearly every day. The symptom scores were summed, which ranged between 0 and 27. A summed score of $\geq 10$ was defined as having symptomatic depression. ${ }^{23}$

\section{Statistical analysis}

All analyses were conducted using SAS V.9.3 (SAS Institute, Cary, North Carolina, USA) and SAS-callable SUDAAN V.11.0.0 (Research Triangle Institute, Research Triangle Park, North Carolina, USA) to account for the complex survey design. To obtain results that would be generalisable to the noninstitutionalised US civilian population, all estimates were weighted to account for the unequal probabilities of selection, oversampling and non-response. The sample weights for the combined 4-year data were constructed by multiplying the provided 2-year mobile examination centre sample weights by one half. ${ }^{24}$

Prevalence (\%) and 95\% CIs for each of the sleep problems were estimated for all study participants combined and stratified by sociodemographic characteristics, health factors, lifestyle factors, job characteristics and certain sleep characteristics. Imputed values for missing components of the sleep quality index ( $\mathrm{n}=10$ participants), ADL score $(\mathrm{n}=200$ participants) and depression score $(n=16)$ were assigned using the method of Raaijmakers. ${ }^{25}$ Imputation of missing items occurred only when at least one component was non-missing. If all components of the scale were missing, no imputation was performed (no imputation was performed for 13 participants on the ADL score and for 544 participants on the depression score; all participants had values for at least one component of the sleep quality index). Wald $\chi^{2}$ tests were used to examine differences in the prevalence of sleep problems across the categories of shiftwork status and across several other covariates. Estimates with a relative $\mathrm{SE}$ (RSE) $>30 \%$ but $\leq 50 \%$ are noted in the tables as they do not meet the NCHS standards of reliability/precision; however, no RSE was $>50 \%$. All comparisons reported in the
Results section are statistically different at a significance level of 0.05 ; however, not all significant differences are reported in the Results section.

Logistic regression analysis was used to examine the relationship between shiftwork status (as the exposure variable) and the binary outcomes of sleep duration, sleep-related ADL score and insomnia. For the sleep quality index, a multinomial logistic regression analysis was used. Simple logistic regression was first performed to assess the relationship between each outcome and the independent variables to identify potential confounders. Multicollinearity was assessed by examining associations among all explanatory variables. A multivariate logistic regression model was fitted for each outcome and included the sociodemographic characteristics of age group, gender, race/ethnicity and education level as well as all other factors that had $\mathrm{p}<0.05$ in the univariate analysis. A backwards elimination approach was next used. Since the models for each sleep outcome were similar with or without further adjustment for physician-diagnosed sleep disorder and frequent use of sleeping pills, only the results without such adjustment are presented. Results are reported using prevalence ratio (PR) and their 95\% CI. A p value of $<0.05$ from the Wald test was considered statistically significant.

\section{RESULTS}

The study sample included 6338 non-institutionalised, US civilian adults (3418 men and 2920 women) who were employed in the week preceding interview. The majority of workers reported that they regularly worked in the daytime $(72.1 \%)$, $4.4 \%$ worked the night shift (representing 6.3 million US workers) and $23.5 \%$ worked on another shift $(6.0 \%$ evening shift, $9.0 \%$ rotating shift and $8.5 \%$ another schedule) with data missing for two workers. The distribution of demographic and continuous sleep variables (ie, sleep duration and sleep latency) is provided in table 1 .

\section{Prevalence of selected sleep-related problems}

The prevalence of short sleep duration was $37.6 \%$ among all workers, representing 54.1 million US workers (table 2). The prevalence of short sleep duration was lower among daytime workers $(35.9 \%)$ compared with night shift $(61.8 \%)$ workers. Of the workers with physician-diagnosed sleep disorders, sleep apnoea had the highest prevalence (3.9\%), followed by insomnia $(0.9 \%)$, restless leg syndrome $(0.3 \%)$ and 'other' types $(1.0 \%)$ (data not shown). The prevalence of prolonged sleep-onset latency $(\geq 30 \mathrm{~min}$ ) was lower among the daytime workers $(31.0 \%)$ compared with the night shift (46.2\%), evening shift $(43 \%)$ and rotating shift $(42.1 \%)$ workers.

The overall prevalence of good, moderate and poor sleep quality among all workers was $53.5 \%, 27.3 \%$ and $19.2 \%$ (ie, representing 76.9, 39.4 and 27.6 million US workers), respectively. Night shift workers had the highest prevalence of poor sleep quality (30.7\%) and workers on another schedule had the highest prevalence of moderate sleep quality (34.1\%) (table 2). Among all workers combined, the prevalence of specific selfreported sleep symptoms varied from $14 \%$ to $27 \%$. Night and evening shift workers compared with the daytime workers had a higher prevalence of frequent trouble falling asleep $(21.7 \%$ and $21.2 \%$, respectively, vs $12.7 \%$, table 2). Night shift workers and those on another schedule also had a higher prevalence of not getting enough sleep $37.2 \%$ and $32.8 \%$, respectively, vs $25.2 \%$ among daytime shift workers, table 2). Compared with the daytime workers, the night shift workers also had a higher prevalence of frequently feeling excessively or overly sleepy during the day ( $22.3 \%$ vs $16.2 \%)$. 
Table 1 Distribution of sociodemographic characteristics, health/lifestyle factors, job characteristics and sleep characteristics among US workers (NHANES, 2005-2008)

$n *$

\begin{tabular}{|c|c|c|c|}
\hline & $n^{*}$ & Weighted $\mathbf{n}$ & $\%(95 \% \mathrm{Cl})$ \\
\hline \multicolumn{4}{|l|}{ Sociodemographic characteristics } \\
\hline \multicolumn{4}{|l|}{ Age group (years) } \\
\hline $18-29$ & 1807 & 35542634 & 24.7 (23.0 to 26.4$)$ \\
\hline $30-39$ & 1374 & 31973309 & 22.2 (20.3 to 24.2$)$ \\
\hline $40-49$ & 1316 & 35275123 & 24.5 (22.7 to 26.4$)$ \\
\hline $50-59$ & 1059 & 28927115 & 20.1 (18.5 to 21.7$)$ \\
\hline$\geq 60$ & 782 & 12291375 & 8.5 (7.6 to 9.5$)$ \\
\hline \multicolumn{4}{|l|}{ Gender } \\
\hline Male & 3418 & 77683523 & 53.9 (52.7 to 55.2$)$ \\
\hline Female & 2920 & 66326035 & 46.1 (44.8 to 47.3 ) \\
\hline \multicolumn{4}{|l|}{ Race/ethnicity } \\
\hline Non-Hispanic white & 2809 & 100189029 & 69.6 (64.8 to 74.1$)$ \\
\hline Non-Hispanic black & 1401 & 15828167 & $11.0(8.4$ to 14.0$)$ \\
\hline Hispanic & 1833 & 19048189 & $13.2(10.9$ to 15.8$)$ \\
\hline Others/multiracial & 295 & 8944173 & 6.2 (5.0 to 7.6$)$ \\
\hline \multicolumn{4}{|l|}{ Marital status } \\
\hline Married/living with partner & 3875 & 94734258 & 66.9 (64.4 to 69.3$)$ \\
\hline Never married & 1388 & 27218138 & 19.2 (17.3 to 21.3$)$ \\
\hline Widowed/divorced/separated & 920 & 19689860 & $13.9(12.7$ to 15.1$)$ \\
\hline \multicolumn{4}{|l|}{ Education level } \\
\hline$<$ High school & 1462 & 21323686 & 14.8 (13.0 to 16.9$)$ \\
\hline$\geq$ High school & 4854 & 122470037 & $85.2(83.1$ to 87.0$)$ \\
\hline \multicolumn{4}{|l|}{ PIRt } \\
\hline$<1$ & 864 & 12264426 & 10.5 (9.2 to 11.9$)$ \\
\hline 1 to $<3$ & 1327 & 22776540 & 19.4 (17.3 to 21.7$)$ \\
\hline$\geq 3$ & 2813 & 82192176 & 70.1 (66.9 to 73.2$)$ \\
\hline \multicolumn{4}{|l|}{ Health factors } \\
\hline \multicolumn{4}{|l|}{ Self-rated health status } \\
\hline Excellent/very good/good & 4941 & 118919466 & 89.4 (88.3 to 90.5$)$ \\
\hline Fair/poor & 873 & 14064200 & $10.6(9.5$ to 11.7$)$ \\
\hline \multicolumn{4}{|l|}{ Body mass index $\ddagger$} \\
\hline$<25.0$ (underweight/normal weight) & 1992 & 47726272 & 33.4 (31.4 to 35.5$)$ \\
\hline 25.0-29.9 (overweight) & 2202 & 48831200 & 34.2 (32.8 to 35.6$)$ \\
\hline$\geq 30.0$ (obese) & 2097 & 46355760 & 32.4 (30.1 to 34.8$)$ \\
\hline \multicolumn{4}{|l|}{ Prescription medication use } \\
\hline No & 3664 & 75463966 & 52.4 (50.5 to 54.3$)$ \\
\hline Yes & 2673 & 68489726 & 47.6 (45.7 to 49.5 ) \\
\hline \multicolumn{4}{|l|}{ Health insurance } \\
\hline No & 1703 & 28751089 & 20.0 (17.7 to 22.5$)$ \\
\hline Yes & 4626 & 115129979 & $80.0(77.5$ to 82.3$)$ \\
\hline \multicolumn{4}{|l|}{ Symptomatic depression } \\
\hline Not symptomatic (PHQ-9<10) & 5496 & 126889653 & 95.8 (95.0 to 96.5$)$ \\
\hline Symptomatic (PHQ-9 $\geq 10)$ & 298 & 5592842 & 4.2 (3.5 to 5.0$)$ \\
\hline \multicolumn{4}{|l|}{ Lifestyle factors } \\
\hline \multicolumn{4}{|l|}{ Smoking status (serum cotinine in $\mathrm{ng} / \mathrm{mL}$ ) } \\
\hline Non-smoker $(\leq 10)$ & 4358 & 98187872 & 72.0 (69.6 to 74.2$)$ \\
\hline Current smoker $(>10)$ & 1595 & 38231850 & 28.0 (25.8 to 30.4$)$ \\
\hline \multicolumn{4}{|l|}{ Alcohol intake§ } \\
\hline None & 813 & 16598864 & $14.1(12.2$ to 16.2$)$ \\
\hline Low/moderate & 3540 & 88561916 & 75.5 (73.6 to 77.3$)$ \\
\hline Excessive & 455 & 12160343 & 10.4 (9.1 to 11.7$)$ \\
\hline \multicolumn{4}{|l|}{ Binge drinking } \\
\hline None & 2274 & 55996888 & $55.6(53.1$ to 58.1$)$ \\
\hline$\leq 12$ days & 913 & 24608873 & 24.4 (22.3 to 26.7$)$ \\
\hline$>12$ days & 804 & 20046680 & 19.9 (17.9 to 22.0$)$ \\
\hline \multicolumn{4}{|l|}{ Caffeine intake (daily average, $\mathrm{mg}$ )** } \\
\hline $0-29.5$ & 1314 & 23655076 & 19.5 (17.7 to 21.4$)$ \\
\hline $29.6-97.0$ & 1319 & 25546591 & 21.0 (19.9 to 22.2$)$ \\
\hline
\end{tabular}


Table 1 Continued

\begin{tabular}{|c|c|c|c|}
\hline & $n^{*}$ & Weighted $\mathbf{n}$ & $\%(95 \% \mathrm{Cl})$ \\
\hline 97.1-208.5 & 1307 & 32050318 & 26.4 (24.9 to 27.9$)$ \\
\hline$>208.5$ & 1308 & 40153064 & 33.1 (30.6 to 35.6$)$ \\
\hline \multicolumn{4}{|l|}{ Job characteristics } \\
\hline \multicolumn{4}{|c|}{ Hours worked in all jobs in preceding week } \\
\hline 1-34 hours (part-time) & 1430 & 28052293 & $20.4(19.2$ to 21.7$)$ \\
\hline 35-47 hours (standard) & 3005 & 67054294 & 48.8 (46.6 to 51.0$)$ \\
\hline$\geq 48$ (long) & 1635 & 42341909 & 30.8 (28.7 to 33.0$)$ \\
\hline \multicolumn{4}{|c|}{ Months worked in current/main job } \\
\hline $0-12$ & 1934 & 38496194 & 26.7 (25.4 to 28.1$)$ \\
\hline $13-48$ & 1613 & 35885117 & 24.9 (23.4 to 26.5$)$ \\
\hline 49-119 & 1177 & 28911552 & 20.1 (18.8 to 21.4$)$ \\
\hline$\geq 120$ & 1610 & 40624276 & 28.2 (25.9 to 30.7$)$ \\
\hline \multicolumn{4}{|l|}{ Occupation categories } \\
\hline White collar & 3117 & 81602165 & 56.7 (53.6 to 59.8$)$ \\
\hline Service & 1427 & 25595560 & $17.8(16.2$ to 19.5$)$ \\
\hline Farm and blue collar & 1782 & 36607064 & 25.5 (23.0 to 28.0$)$ \\
\hline \multicolumn{4}{|l|}{ Sleep characteristics } \\
\hline \multicolumn{4}{|c|}{ Sleep duration per weekday/workday } \\
\hline$<7$ hours & 2512 & 54119388 & 37.6 (35.2 to 40.0$)$ \\
\hline $7-9$ hours & 3724 & 87945034 & 61.1 (58.6 to 63.5$)$ \\
\hline 10 or more hours & 101 & 1934837 & $1.3(1.0$ to 1.8$)$ \\
\hline \multicolumn{4}{|c|}{ Sleep latency (time required to fall asleep) } \\
\hline $0-10 \mathrm{~min}$ & 2873 & 67745916 & 47.1 (44.9 to 49.3 ) \\
\hline $11-29 \min$ & 1232 & 28723589 & 20.0 (18.6 to 21.5$)$ \\
\hline $30-59 \min$ & 1371 & 30593742 & $21.3(19.7$ to 22.9$)$ \\
\hline 60 or more $\min$ & 849 & 16722239 & 11.6 (10.6 to 12.8$)$ \\
\hline \multicolumn{4}{|c|}{ Physician-diagnosed sleep disordert† } \\
\hline No & 5986 & 134884353 & 93.8 (93.0 to 94.5$)$ \\
\hline Yes & 343 & 8943077 & 6.2 (5.5 to 7.0 ) \\
\hline \multicolumn{4}{|c|}{ Sleeping pills or other medication use to help with sleep (times/previous month) } \\
\hline 0 & 5455 & 120602534 & 83.8 (82.8 to 84.7$)$ \\
\hline$>0$ to $<5$ & 555 & 14140653 & $9.8(8.8$ to 10.9$)$ \\
\hline$\geq 5$ & 327 & 9235618 & 6.4 (5.6 to 7.3$)$ \\
\hline \multicolumn{4}{|c|}{$\begin{array}{l}\text { *Unweighted sample size. } \\
\text { tPIR is calculated as the ratio of self-reported family income to the poverty threshold level according to US Census Bureau poverty guidelines. } \\
\text { ‡Body mass index=measured weight in kilograms/(measured height in metres) } \\
\text { §Self-reported alcohol intake for the } 12 \text { months that preceded interview was determined for participants aged } \geq 20 \text { years. Alcohol intake was categorised as: excessive ( }>2 \text { drinks } \\
\text { day for men and }>1 \text { drink per day for women), low/moderate ( }>0 \text { but }<2 \text { drinks per day for men and } \leq 1 \text { drink per day for women) and none. } \\
\text { ๆBinge drinking=days in preceding year that participant consumed five or more alcoholic drinks in a single day. } \\
\text { **Calculated from fluid (coffee, tea and soda) and food sources (chocolate) reported in two } 24 \text {-hour dietary recalls, and categorised into quartiles based on intake distribution. } \\
\text { ††Participant ever told by a doctor or other health professional that they had a sleep disorder, including sleep apnoea, insomnia, restless leg syndrome or 'other'. } \\
\text { NHANES, National Health and Nutrition Examination Survey; PHQ-9, Patient Health Questionnaire-9; PIR, poverty income ratio. }\end{array}$} \\
\hline
\end{tabular}

The prevalence of impaired sleep-related ADL was 24.8\% among all workers (ie, 35.6 million US workers) with a higher prevalence among the night shift (36.2\%) compared with daytime $(23.7 \%)$ workers. The prevalence of insomnia was $8.8 \%$ among all workers (ie, representing 12.7 million US workers) with a higher prevalence among the night shift (18.5\%) compared with daytime (8.4\%) workers.

\section{Sleep-related problems by sleep duration and shift}

Among all workers combined, those who sleep $<7$ hours were more likely to have poor sleep quality, impaired ADL and insomnia compared to those who sleep 7 hours or more (figure 1). This finding was also true for day shift workers, night shift workers, rotating shift workers and workers of another schedule. Among regular night shift workers who sleep $<7$ hours, the prevalence of each sleep problem was higher compared to day shift workers in the same sleep duration category.

\section{Predictors of selected sleep-related problems}

Workers aged $\geq 60$ years had a lower prevalence of short sleep duration, impaired sleep-related ADL and insomnia compared with those aged 30-59 years (table 3). Female workers had a lower prevalence of short sleep duration but higher prevalence of the other three sleep outcomes compared to male workers. Workers with PIR $\geq 3$ had a lower prevalence of poor sleep quality, impaired sleep-related ADL and insomnia compared with those with PIR $<1$. Obese workers had a higher prevalence of short sleep duration and poor sleep quality compared with those who were normal weight/underweight. Current smokers had a higher prevalence of short sleep duration, poor sleep quality and insomnia (but not impaired sleep-related ADL) compared with non-smokers. Workers who worked $\geq 48$ hours had a higher prevalence of short sleep duration, poor sleep quality and insomnia compared with those who worked $<48$ hours per week. Workers with frequent use of sleeping pills had a higher prevalence of poor sleep quality, impaired sleep-related ADL 
Table 2 Weighted prevalence of selected sleep-related problems and job characteristics by usual shift worked among US workers (NHANES, 2005-2008)

\begin{tabular}{|c|c|c|c|c|c|c|c|c|c|c|c|c|}
\hline & \multirow{2}{*}{\multicolumn{2}{|c|}{ Total $(n=6338)$}} & \multicolumn{10}{|c|}{ Shiftwork status* } \\
\hline & & & \multicolumn{2}{|c|}{$\begin{array}{l}\text { Regular daytime shift } \\
(\mathrm{n}=4568)\end{array}$} & \multicolumn{2}{|c|}{$\begin{array}{l}\text { Regular night shift } \\
(\mathrm{n}=277)\end{array}$} & \multicolumn{2}{|c|}{$\begin{array}{l}\text { Regular evening shift } \\
(\mathrm{n}=381)\end{array}$} & \multicolumn{2}{|c|}{ Rotating shift $(n=570)$} & \multicolumn{2}{|c|}{$\begin{array}{l}\text { Another schedulet } \\
(\mathrm{n}=540)\end{array}$} \\
\hline & $\mathrm{n} \ddagger$ & $\%(95 \% \mathrm{Cl})$ & $\mathbf{n}$ & $\%(95 \% \mathrm{Cl})$ & $\mathrm{n}$ & $\%(95 \% \mathrm{Cl})$ & n & $\%(95 \% \mathrm{Cl})$ & $\mathbf{n}$ & $\%(95 \% \mathrm{Cl})$ & n & $\%(95 \% \mathrm{Cl})$ \\
\hline \multicolumn{13}{|l|}{ Sleep-related problems } \\
\hline Short sleep duration $(<7$ hours per weekday/workday)§ & 2512 & 37.6 (35.3 to 39.9$)$ & 1717 & 35.9 (33.5 to 38.4$)$ & 172 & $61.8(55.0$ to 68.3$)$ & 157 & 39.1 (33.2 to 45.0$)$ & 248 & 41.3 (35.5 to 47.1$)$ & 217 & $37.1(31.7$ to 42.5$)$ \\
\hline Physician-diagnosed sleep disorder & 343 & $6.2(5.5$ to 7.0$)$ & 248 & $6.5(5.8$ to 7.3$)$ & 15 & $3.8(1.9 \text { to } 7.6)^{* *}$ & 19 & $4.4(1.2 \text { to } 7.6)^{* *}$ & 26 & $5.9(2.7$ to 9.2$)$ & 35 & 6.2 (3.0 to 9.4$)$ \\
\hline $\begin{array}{l}\text { Sleeping pills/other medications to help with sleep (five or } \\
\text { more times in preceding month) }\end{array}$ & 327 & $6.4(5.6$ to 7.3$)$ & 238 & $6.4(5.5$ to 7.5$)$ & 16 & $8.1(5.4$ to 12.2$)$ & 18 & $6.4(3.2$ to 9.7$)$ & 26 & $5.9(3.2$ to 8.6$)$ & 29 & 6.2 (4.0 to 8.4$)$ \\
\hline Sleep latency/time to sleep at bedtime $(\geq 30 \mathrm{~min}) \S$ & 2220 & 32.9 (30.9 to 35.0$)$ & 1514 & $31.0(29.0$ to 33.0$)$ & 118 & 46.2 (39.9 to 52.6$)$ & 167 & 43.0 (36.8 to 49.3 ) & 252 & 42.1 (36.4 to 47.8$)$ & 168 & $29.6(23.0$ to 36.2$)$ \\
\hline Ever told physician had trouble falling asleep & 1103 & 20.2 (19.2 to 21.2$)$ & 782 & $19.8(18.6$ to 21.0$)$ & 49 & $22.2(15.0$ to 31.5$)$ & 60 & 15.9 (11.0 to 20.8$)$ & 96 & $21.8(16.6$ to 27.1$)$ & 116 & 24.1 (18.7 to 29.6$)$ \\
\hline \multicolumn{13}{|l|}{ Sleep quality, self-reported (five or more times in the past month) } \\
\hline Trouble falling asleep§ & 824 & $14.0(12.8$ to 15.2$)$ & 534 & $12.7(11.4$ to 14.1$)$ & 54 & 21.7 (16.7 to 27.5$)$ & 73 & $21.2(15.6$ to 26.8$)$ & 92 & 17.5 (12.4 to 22.7$)$ & 71 & $14.4(10.5$ to 18.2$)$ \\
\hline $\begin{array}{l}\text { Wake up during the night with trouble getting back to } \\
\text { sleep }\end{array}$ & 1015 & 17.4 (16.1 to 18.8$)$ & 718 & 17.1 (15.7 to 18.5$)$ & 52 & 19.9 (14.2 to 27.2$)$ & 65 & 19.0 (13.7 to 24.2$)$ & 81 & 14.9 (11.6 to 18.2$)$ & 99 & 20.2 (15.7 to 24.8$)$ \\
\hline $\begin{array}{l}\text { Wake up too early in the morning and unable to get back } \\
\text { to sleep§}\end{array}$ & 874 & $14.3(13.0$ to 15.6$)$ & 633 & 14.2 (12.8 to 15.7$)$ & 46 & 20.6 (14.8 to 27.9$)$ & 52 & $15.0(11.0$ to 19.0$)$ & 61 & $9.7(7.2$ to 12.3$)$ & 82 & $15.7(12.1$ to 19.3$)$ \\
\hline Feel unrested during the day regardless of hours of sleep & 1528 & 26.6 (25.1 to 28.2$)$ & 1054 & 25.5 (23.6 to 27.4$)$ & 75 & $32.1(25.2$ to 40.0$)$ & 100 & 28.7 (22.0 to 35.4$)$ & 155 & 28.5 (21.2 to 35.8$)$ & 144 & $31.4(27.3$ to 35.6$)$ \\
\hline Feel excessively or overly sleepy during the day & 1020 & 17.0 (15.5 to 18.5$)$ & 695 & $16.2(14.7$ to 17.8$)$ & 56 & 22.3 (17.5 to 27.9$)$ & 64 & 17.6 (11.7 to 23.4$)$ & 104 & 17.5 (12.5 to 22.4$)$ & 101 & 20.7 (16.3 to 25.1$)$ \\
\hline Not getting enough sleep§ & 1587 & 26.9 (25.3 to 28.5$)$ & 1061 & 25.2 (23.4 to 27.1 ) & 92 & 37.2 (31.6 to 43.2 ) & 122 & 31.9 (26.7 to 37.2$)$ & 159 & 27.6 (20.9 to 34.3 ) & 153 & 32.8 (28.2 to 37.4$)$ \\
\hline \multicolumn{13}{|l|}{ Sleep quality index§, $† \dagger$} \\
\hline Good & 3555 & 53.5 (52.0 to 54.9$)$ & 2646 & 55.2 (53.2 to 57.3 ) & 142 & 46.9 (39.9 to 54.0$)$ & 192 & $48.0(40.0$ to 56.0$)$ & 299 & 50.7 (44.1 to 57.3$)$ & 274 & 47.2 (42.5 to 51.9$)$ \\
\hline Moderate & 1620 & 27.3 (25.8 to 28.9$)$ & 1120 & 26.4 (24.5 to 28.4$)$ & 60 & 22.4 (17.4 to 28.2$)$ & 107 & 28.9 (23.8 to 34.0$)$ & 165 & 30.1 (24.3 to 35.8$)$ & 168 & 34.1 (29.0 to 39.3$)$ \\
\hline Poor & 1163 & 19.2 (17.6 to 20.8$)$ & 802 & 18.4 (17.0 to 19.9$)$ & 75 & 30.7 (25.7 to 36.2 ) & 82 & 23.1 (16.8 to 29.3 ) & 106 & 19.3 (14.2 to 24.3$)$ & 98 & 18.7 (13.9 to 23.5$)$ \\
\hline \multicolumn{13}{|l|}{ Sleep-related ADL } \\
\hline Difficulty concentrating & 1387 & 22.9 (21.5 to 24.3$)$ & 942 & 22.1 (20.8 to 23.5 ) & 83 & 30.4 (22.9 to 39.0$)$ & 95 & 22.5 (16.6 to 28.4 ) & 122 & 22.0 (16.9 to 27.1$)$ & 144 & 26.7 (21.1 to 32.3$)$ \\
\hline Difficulty remembering§ & 1086 & 17.3 (16.2 to 18.5$)$ & 734 & 16.4 (15.1 to 17.7$)$ & 67 & 25.7 (20.4 to 31.9 ) & 79 & 18.4 (13.6 to 23.1$)$ & 89 & 16.0 (12.1 to 20.0$)$ & 117 & 22.5 (18.6 to 26.3 ) \\
\hline Difficulty eating & 207 & $2.8(2.3$ to 3.3$)$ & 129 & 2.3 (1.9 to 2.8$)$ & 15 & $3.2(1.6 \text { to } 6.3)^{* *}$ & 22 & 6.3 (2.8 to 9.8$)$ & 27 & $4.6(2.1$ to 7.0$)$ & 14 & $2.6(0.8 \text { to } 4.3)^{* *}$ \\
\hline Difficulty with a hobby & 782 & 13.4 (12.3 to 14.6$)$ & 531 & 13.2 (12.0 to 14.4$)$ & 48 & 18.6 (14.0 to 24.3$)$ & 51 & 12.2 (7.7 to 16.7$)$ & 77 & 14.8 (10.9 to 18.8$)$ & 75 & 13.0 (9.2 to 16.8$)$ \\
\hline Difficulty getting things done because too sleepy to drive & 721 & $11.3(10.3$ to 12.3$)$ & 465 & $10.5(9.5$ to 11.5$)$ & 46 & 16.9 (11.8 to 23.7$)$ & 60 & $13.2(8.3$ to 18.1$)$ & 70 & 11.3 (8.1 to 14.6$)$ & 80 & $14.3(10.1$ to 18.6$)$ \\
\hline Difficulty with finance & 749 & 11.9 (10.7 to 13.2$)$ & 478 & 11.3 (10.1 to 12.6$)$ & 34 & 13.4 (8.5 to 20.5 ) & 68 & 12.9 (9.7 to 16.2$)$ & 83 & 12.5 (8.7 to 16.4 ) & 86 & 15.4 (11.5 to 19.3$)$ \\
\hline Difficulty with paid or volunteer work & 632 & $10.5(9.6$ to 11.4$)$ & 436 & $10.4(9.3$ to 11.7$)$ & 37 & 13.1 (8.7 to 19.2$)$ & 47 & $11.2(7.9$ to 14.6$)$ & 57 & $8.7(6.4$ to 11.0$)$ & 55 & $10.8(7.5$ to 14.0$)$ \\
\hline Difficulty maintaining phone conversation§ & 605 & $8.4(7.5$ to 9.4$)$ & 360 & $7.1(6.2$ to 8.0$)$ & 46 & $15.0(10.2$ to 21.6$)$ & 58 & $14.2(9.8$ to 18.5$)$ & 80 & 12.7 (8.5 to 16.8$)$ & 61 & $10.0(6.6$ to 13.4$)$ \\
\hline Impaired ADL score§, & 1545 & 24.8 (23.1 to 26.5$)$ & 1030 & 23.7 (22.2 to 25.3$)$ & 97 & $36.2(28.8$ to 44.4$)$ & 118 & 29.1 (23.1 to 35.1$)$ & 147 & 23.5 (18.5 to 28.4$)$ & 153 & $27.7(22.3$ to 33.1$)$ \\
\hline Insomnia§,§§ & 537 & 8.8 (7.9 to 9.8$)$ & 368 & 8.4 (7.5 to 9.5$)$ & 41 & 18.5 (13.2 to 25.4$)$ & 36 & 9.7 (6.6 to 12.8 ) & 48 & 9.3 (5.9 to 12.8 ) & 44 & $7.0(4.3$ to 9.7$)$ \\
\hline \multicolumn{13}{|l|}{ Job characteristics } \\
\hline Hours worked in all jobs in preceding week $(\geq 48) \S$ & 1635 & $30.8(28.7$ to 33.0$)$ & 1155 & 30.0 (27.9 to 32.3$)$ & 80 & 29.8 (24.6 to 35.6$)$ & 65 & 22.2 (17.7 to 26.7$)$ & 149 & 29.6 (24.6 to 34.6$)$ & 186 & 43.7 (38.1 to 49.4$)$ \\
\hline Years worked in current/main job ( $\geq 10$ years)§ & 1610 & 28.2 (25.9 to 30.6$)$ & 1261 & 29.9 (27.3 to 32.6$)$ & 45 & 15.1 (10.4 to 21.3$)$ & 47 & 13.1 (7.4 to 18.7$)$ & 81 & 19.8 (14.0 to 25.7$)$ & 176 & 36.1 (30.0 to 42.2$)$ \\
\hline
\end{tabular}




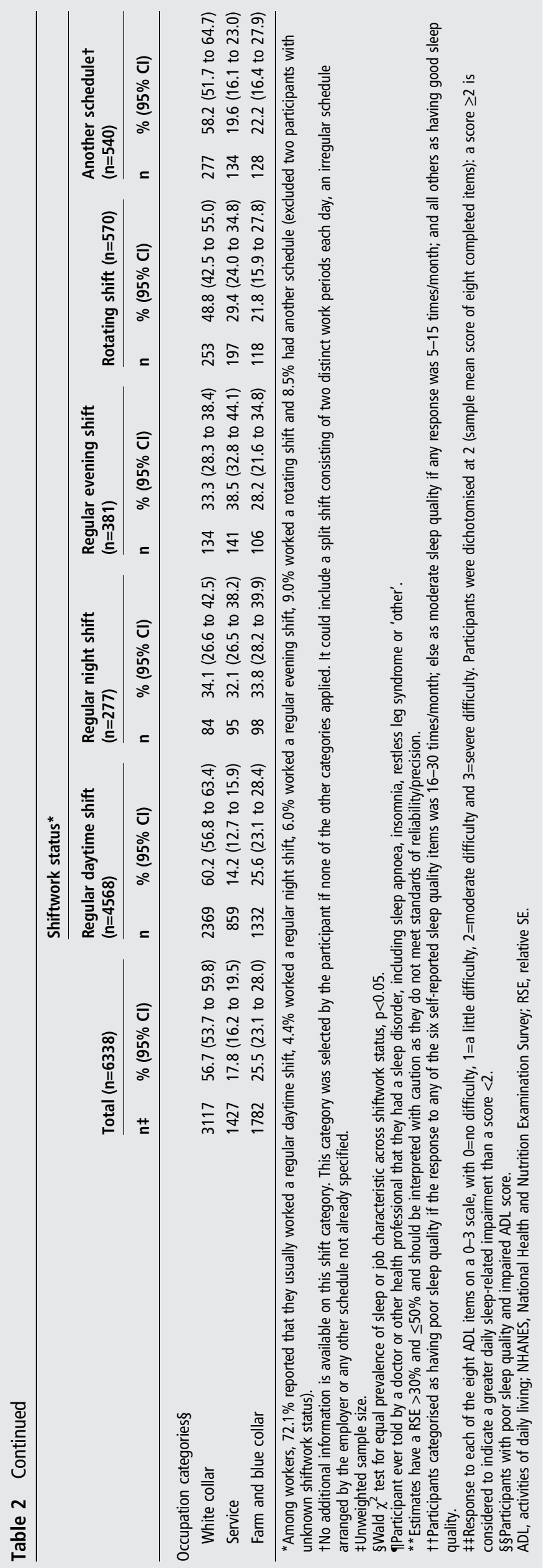

and insomnia (but not short sleep duration) compared to those without. Finally, compared to workers without these characteristics, a higher prevalence of all four sleep outcomes was observed among workers who were widowed, divorced or separated; workers who reported fair or poor health; workers with symptomatic depression; and workers who had a physiciandiagnosed sleep disorder.

\section{Modelling of sleep problems and shiftwork status}

Compared with daytime workers, night shift workers were more likely to have short sleep duration (model 2: $\mathrm{PR}=1.70$; 95\% CI 1.48 to 1.96 ) (table 4). The likelihood of poor self-reported sleep quality, impaired sleep-related ADL and insomnia was higher among night shift workers compared with daytime workers ( $\mathrm{PR}=1.52,1.39$ and 2.03, respectively). The likelihood of moderate self-reported sleep quality was higher among workers on another schedule compared with daytime workers (model 2: $\mathrm{PR}=1.25 ; 95 \%$ CI 1.06 to 1.47 ).

\section{DISCUSSION}

Using 2005-2008 NHANES data, we found that sleep-related problems were common in a nationally representative sample of US adult workers. Furthermore, night shift workers had a higher risk for all of these sleep problems, and these higher risks persisted after adjustment for potential confounders, including long work hours ( $\geq 48$ hours/week), sociodemographic characteristics and health/lifestyle/work factors.

Although it has long been recognised that shift workers, particularly those working in the night shift, have more sleep problems or sleepiness than daytime workers, ${ }^{12} 1326$ to the best of our knowledge, this is the first study to use a nationally representative sample of the US working population to examine the role of shiftwork on sleep quality, sleep-related ADL and insomnia. The sleep problems we observed may be explained by a desynchronisation between the circadian system and the sleep/ wake cycle that has been detected in night shift workers. ${ }^{12} 27$ Although we only reported on the sleep problems present at the time of interview, the sleep problems observed among night shift workers may not quickly reverse by switching to day shift. Instead, the effects of shiftwork on sleep duration and sleep quality may persist into retirement, ${ }^{28}$ although this is disputed by others. $^{29}$

Sleep-related problems were significantly more prevalent among those with short sleep duration, especially among night shift workers (figure 1), consistent with previous reports. In the general population, it has previously been found that sleep duration is lower among those with insomnia, ${ }^{30}$ and those with short sleep duration are more likely to have impaired $\mathrm{ADL}^{31}$ and poor sleep quality. ${ }^{32}$ This coexistence of short sleep duration with other sleep problems is cause for concern. For example, there appears to be a synergism between short sleep duration and poor sleep quality in their effect on health outcomes, as those with both had the highest risk for coronary heart disease ${ }^{3}$ and all-cause mortality. ${ }^{4}$

We found that $25 \%$ of all workers have sleep-related ADL impairment, similar to that observed for the general population, ${ }^{31}$ which rose to $36 \%$ among regular night shift workers. Such impairment of ADL activities and poor sleep quality may contribute to some of the adverse outcomes observed among night shift workers, including increased fatal and non-fatal injury rates, ${ }^{33}$ reckless behaviour (eg, unsafe driving, excessive drinking, poor diet and higher smoking prevalence) and impaired work performance. ${ }^{34}$ For example, the reasons for an 


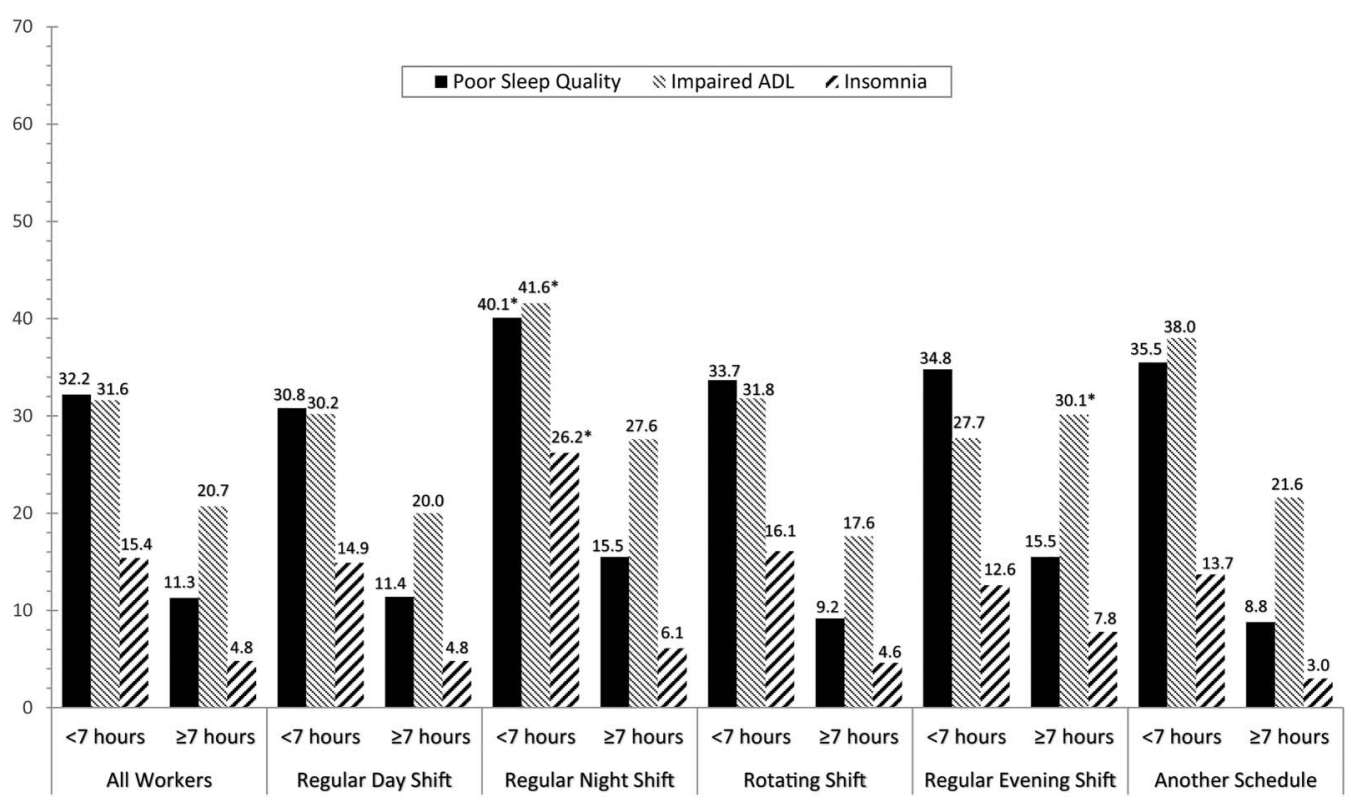

Figure 1 Weighted prevalence (\%) of poor sleep quality, impaired ADL and insomnia by usual sleep duration and shift-USA (NHANES, 20052008). *Wald $\chi^{2}$ test for equal prevalence of sleep characteristics between the designated shift and regular day shift in the same sleep duration, $\mathrm{p}<0.05$. ADL, activities of daily living; NHANES, National Health and Nutrition Examination Survey.

elevated smoking prevalence among shift workers may include its effects on relieving fatigue and sleepiness. ${ }^{35}$

Prevalence estimates of short sleep duration from nationally representative samples of US workers vary. While we reported a prevalence of $38 \%$ using NHANES data, the 2004-2007 ${ }^{14}$ and $2010^{15}$ National Health Interview Survey (NHIS) reported a 30\% prevalence among US workers, which are in line with estimates for the general US population from NHANES and NHIS, respectively. ${ }^{31} 36$ The NHANES and NHIS discrepancies may be due to the difference in how these surveys ask about sleep duration. NHANES asks about the amount of sleep obtained at night on weekdays or workdays, whereas NHIS asks 'on average, how many hours of sleep do you get in a 24-hour period?'. Since NHANES only asked about amount of sleep 'at night', night shift workers may have difficulty with their response since they typically do not sleep at night. This may also explain why the prevalence estimates for short sleep duration among night shift workers differed between our study $(62 \%)$ and NHIS (44\%). ${ }^{15}$ In addition, NHANES asked about sleep duration on workdays, whereas NHIS asked about 'a 24-hour period' without distinguishing between workdays and non-workdays. The amount of sleep obtained on a workday may be a better measure of work-related short sleep duration.

Insomnia is a disorder that involves poor sleep quality and impaired sleep-related ADL function. ${ }^{21}$ In contrast to sleep duration, few estimates on insomnia prevalence in the working population exist. The APA reported that $6-10 \%$ of the US population has insomnia disorder, ${ }^{21}$ which is consistent with the $9 \%$ prevalence we found among US workers. However, in a study of workers enrolled in a national US commercial health plan between 2008 and 2009, self-reported insomnia prevalence was $23 \% .^{5}$ Kessler et $a l^{5}$ defined insomnia in a manner more consistent with the APA definition (eg, their definition required night-time symptoms occurring three or more times/week vs NHANES data which can identify high frequency sleep symptoms only when they occurred at least 16 times per month). Neither Kessler $e t a l^{5}$ nor our study included two other APA definitional criteria for insomnia: sleep difficulty present at least 3 months and exclusion of secondary insomnia.

\section{Study limitations}

This study has several limitations. First, the cross-sectional design limits making inferences regarding the direction of our observed sleep-shiftwork association; for example, there may be selfselection into a given shift according to sleep characteristics. Second, our findings are based on self-reports and may be prone to misclassification bias. For example, comparisons of sleep duration based on self-reports versus actigraphy and polysomnography have shown that self-reports often overestimate sleep duration, except those with short sleep duration often underestimate sleep duration. ${ }^{37}{ }^{38}$ Fortunately, these earlier studies comparing self-report and objective sleep duration suggest that our distribution of dichotomised sleep duration may be accurate. Third, although we are not aware of studies to establish the psychometric properties of the sleep quality index we used, it has been used previously to examine the effect of sleep quality on hypertension. ${ }^{18}$ Fourth, data were incomplete for several covariates. The exclusion of workers with missing covariates may result in selection bias and residual confounding by unmeasured covariates. However, we think the potential for such bias and confounding is low because the magnitude of the association between shiftwork status and sleep problems remained essentially unchanged with or without adjustment for various sociodemographic/lifestyle/work factors. Fifth, there is a possibility that night shift workers' response to some sleep questions, such as 'waking too early in the morning' and 'feeling excessively sleepy during the day', may be inaccurate as they likely slept during the day. Finally, due to a lack of data, we were unable to evaluate shift characteristics (eg, number of years employed on a given shift; speed, direction and pattern of rotating shifts; and amount of time off between shifts) and due to small sample size, we were unable to evaluate detailed industry and occupation categories, each of which may modify the association between shiftwork and sleep. For example, those with a long tenure on night shift may be more tolerant of that shift as demonstrated by the absence of an elevated injury risk among such workers. ${ }^{39}$ 
Table 3 Weighted prevalence of short sleep duration, poor sleep quality, poor sleep-related ADL score and insomnia among US workers by sociodemographic characteristics, health/lifestyle factors, and job and sleep characteristics (NHANES, 2005-2008)

\begin{tabular}{|c|c|c|c|c|c|c|c|c|c|c|c|c|}
\hline & \multicolumn{3}{|c|}{ Short sleep duration* } & \multicolumn{3}{|c|}{ Poor sleep quality $\dagger$} & \multicolumn{3}{|c|}{ Poor sleep-related ADL scoreł } & \multicolumn{3}{|c|}{ Insomnia§ } \\
\hline & nף & $\%(95 \% \mathrm{Cl})$ & $\mathrm{p}$ Value & $\mathrm{n}$ & $\%(95 \% \mathrm{Cl})$ & $\mathrm{p}$ Value & $\mathrm{n}$ & $\%(95 \% \mathrm{Cl})$ & $p$ Value & $\mathrm{n}$ & $\%(95 \% \mathrm{Cl})$ & $\mathrm{p}$ Value \\
\hline Total & 2512 & 37.6 (35.3 to 39.9 ) & - & 1163 & 19.2 (17.6 to 20.8$)$ & - & 1545 & 24.8 (23.1 to 26.5$)$ & - & 537 & $8.8(7.9$ to 9.8$)$ & - \\
\hline \multicolumn{13}{|l|}{ Sociodemographic characteristics } \\
\hline Age group (years) & & & 0.036 & & & 0.084 & & & 0.001 & & & 0.027 \\
\hline $18-29$ & 620 & 35.1 (31.9 to 38.2 ) & & 336 & 19.9 (17.3 to 22.5$)$ & & 522 & 28.6 (24.9 to 32.3$)$ & & 173 & 9.7 (7.9 to 11.4$)$ & \\
\hline $30-39$ & 559 & 38.6 (34.7 to 42.5$)$ & & 275 & 20.7 (18.0 to 23.4$)$ & & 330 & 24.1 (21.5 to 26.7$)$ & & 119 & $8.6(7.1$ to 10.0$)$ & \\
\hline $40-49$ & 572 & 39.0 (35.5 to 42.5 ) & & 244 & 18.1 (15.6 to 20.6$)$ & & 328 & $24.2(21.3$ to 27.0$)$ & & 116 & 8.7 (6.5 to 10.8$)$ & \\
\hline $50-59$ & 457 & 39.5 (35.9 to 43.2 ) & & 202 & 19.7 (16.8 to 22.6$)$ & & 243 & 25.1 (22.0 to 28.2$)$ & & 94 & 9.8 (7.9 to 11.7$)$ & \\
\hline Gender & & & 0.001 & & & 0.001 & & & 0.001 & & & 0.002 \\
\hline Male & 1426 & 40.4 (37.9 to 43.0$)$ & & 529 & 16.3 (14.7 to 18.0$)$ & & 713 & 21.7 (19.7 to 23.8$)$ & & 228 & 7.2 (5.9 to 8.6$)$ & \\
\hline Female & 1086 & 34.3 (31.4 to 37.3 ) & & 634 & 22.6 (20.1 to 25.2 ) & & 832 & 28.4 (25.9 to 31.0$)$ & & 309 & $10.7(9.3$ to 12.3$)$ & \\
\hline Race/ethnicity & & & 0.001 & & & 0.001 & & & 0.001 & & & 0.091 \\
\hline Non-Hispanic white & 974 & 34.9 (32.2 to 37.8 ) & & 586 & 20.3 (18.4 to 22.4$)$ & & 702 & 24.6 (22.7 to 26.7$)$ & & 259 & $9.2(8.1$ to 10.5$)$ & \\
\hline Non-Hispanic black & 774 & 55.4 (52.5 to 58.3 ) & & 254 & 18.4 (16.3 to 20.8$)$ & & 374 & 27.6 (23.4 to 32.3 ) & & 123 & 8.9 (7.4 to 10.6$)$ & \\
\hline Hispanic & 638 & 34.9 (32.0 to 37.9 ) & & 263 & $14.4(12.5$ to 16.5$)$ & & 374 & 19.8 (18.0 to 21.8 ) & & 125 & 6.7 (5.3 to 8.3$)$ & \\
\hline Others/multiracial & 126 & 41.5 (34.5 to 48.9$)$ & & 60 & 17.7 (13.3 to 23.2$)$ & & 95 & 31.9 (26.8 to 37.5 ) & & 30 & 8.9 (5.6 to 13.7$)$ & \\
\hline Marital status & & & 0.020 & & & 0.041 & & & 0.001 & & & 0.010 \\
\hline Widowed/divorced/separated & 420 & 43.7 (38.7 to 48.9 ) & & 204 & 23.4 (19.4 to 28.1$)$ & & 260 & 29.8 (26.1 to 33.7$)$ & & 108 & 13.1 (10.3 to 16.4$)$ & \\
\hline Education level & & & 0.660 & & & 0.001 & & & 0.288 & & & 0.854 \\
\hline$<$ High school & 542 & 36.9 (32.8 to 41.1 ) & & 259 & 18.3 (15.8 to 21.0$)$ & & 315 & 22.9 (19.6 to 26.6$)$ & & 123 & 8.6 (6.8 to 10.9$)$ & \\
\hline$\geq$ High school & 1964 & 37.7 (35.4 to 40.1$)$ & & 902 & 19.4 (17.7 to 21.1$)$ & & 1226 & 25.1 (23.3 to 27.1$)$ & & 412 & 8.8 (7.9 to 9.9$)$ & \\
\hline PIR & & & 0.057 & & & 0.019 & & & 0.041 & & & 0.040 \\
\hline$<1$ & 327 & 38.0 (33.2 to 43.0$)$ & & 183 & 23.3 (20.2 to 26.7 ) & & 236 & 28.5 (22.9 to 34.8 ) & & 92 & 11.5 (8.9 to 14.6$)$ & \\
\hline 1 to $<3$ & 550 & 40.0 (36.2 to 44.0$)$ & & 246 & 20.2 (17.4 to 23.3 ) & & 334 & 28.0 (24.4 to 32.0 ) & & 120 & 9.8 (7.8 to 12.1$)$ & \\
\hline$\geq 3$ & 1070 & 34.9 (32.1 to 37.8 ) & & 481 & 17.9 (16.1 to 19.8$)$ & & 639 & 23.0 (21.3 to 24.7$)$ & & 204 & 7.7 (6.7 to 8.8$)$ & \\
\hline \multicolumn{13}{|l|}{ Health factors } \\
\hline Self-rated health status & & & 0.001 & & & 0.001 & & & 0.001 & & & 0.001 \\
\hline Excellent/very good/good & 1873 & 36.1 (33.8 to 38.6 ) & & 837 & 17.8 (16.5 to 19.3$)$ & & 1125 & 23.3 (21.5 to 25.2 ) & & 370 & 7.9 (7.0 to 8.8 ) & \\
\hline Fair/poor & 410 & 46.6 (41.6 to 51.8 ) & & 236 & 30.9 (26.8 to 35.4 ) & & 287 & 35.2 (31.4 to 39.3 ) & & 119 & 15.1 (12.1 to 18.6$)$ & \\
\hline Body mass index & & & 0.001 & & & 0.044 & & & 0.814 & & & 0.422 \\
\hline$<25.0$ (underweight/normal weight) & 657 & 31.9 (28.5 to 35.5$)$ & & 345 & 18.7 (16.5 to 21.1$)$ & & 495 & 25.5 (22.8 to 28.3 ) & & 153 & $7.9(6.6$ to 9.5$)$ & \\
\hline 25.0-29.9 (overweight) & 887 & 38.0 (35.6 to 40.6$)$ & & 371 & 17.5 (15.5 to 19.7$)$ & & 517 & 24.5 (22.6 to 26.5 ) & & 180 & 9.1 (7.7 to 10.7$)$ & \\
\hline$\geq 30.0$ (obese) & 950 & 42.9 (39.7 to 46.2$)$ & & 434 & 21.3 (18.4 to 24.4$)$ & & 521 & 24.5 (22.0 to 27.2$)$ & & 198 & 9.4 (7.9 to 11.1$)$ & \\
\hline Prescription medication use & & & 0.565 & & & 0.001 & & & 0.001 & & & 0.001 \\
\hline No & 1417 & 37.9 (35.6 to 40.2 ) & & 592 & 16.3 (15.0 to 17.5$)$ & & 837 & 22.7 (21.2 to 24.3$)$ & & 270 & $7.2(6.4$ to 8.0$)$ & \\
\hline Yes & 1094 & $37.2(34.4$ to 40.1$)$ & & 571 & 22.4 (20.1 to 24.9 ) & & 708 & 27.0 (24.8 to 29.5 ) & & 267 & $10.6(9.2$ to 12.3$)$ & \\
\hline Yes & 1865 & 36.9 (34.5 to 39.4$)$ & & 836 & 18.5 (17.0 to 20.1$)$ & & 1158 & 24.9 (23.3 to 26.6$)$ & & 386 & 8.6 (7.8 to 9.4$)$ & \\
\hline Symptomatic depression & & & 0.001 & & & 0.001 & & & 0.001 & & & 0.001 \\
\hline Not symptomatic (PHQ-9<10) & 2109 & 36.4 (34.1 to 38.7 ) & & 929 & 17.8 (16.3 to 19.3$)$ & & 1237 & 23.0 (21.3 to 24.9$)$ & & 398 & $7.5(6.6$ to 8.6$)$ & \\
\hline Symptomatic (PHG-9 $\geq 10$ ) & 165 & $54.7(47.6$ to 61.7$)$ & & 138 & $52.0(43.7$ to 60.1$)$ & & 171 & 59.6 (51.6 to 67.1$)$ & & 89 & 33.5 (26.3 to 41.6$)$ & \\
\hline
\end{tabular}




\begin{tabular}{|c|c|c|c|c|c|c|c|c|c|c|c|c|}
\hline & \multicolumn{3}{|c|}{ Short sleep duration* } & \multicolumn{3}{|c|}{ Poor sleep quality $\dagger$} & \multicolumn{3}{|c|}{ Poor sleep-related ADL score‡ } & \multicolumn{3}{|c|}{ Insomnia§ } \\
\hline & nๆ & $\%(95 \% \mathrm{Cl})$ & $\mathrm{p}$ Value & $\mathbf{n}$ & $\%(95 \% \mathrm{Cl})$ & $\mathrm{p}$ Value & $\mathbf{n}$ & $\%(95 \% \mathrm{Cl})$ & $\mathrm{p}$ Value & $\mathbf{n}$ & $\%(95 \% \mathrm{Cl})$ & $\mathrm{p}$ Value \\
\hline \multicolumn{13}{|l|}{ Lifestyle factors } \\
\hline Smoking status (cotinine in $\mathrm{ng} / \mathrm{mL}$ ) & & & 0.001 & & & 0.001 & & & 0.493 & & & 0.008 \\
\hline Non-smoker $(\leq 10)$ & 1649 & 34.8 (32.6 to 37.2 ) & & 725 & 17.2 (15.6 to 18.9$)$ & & 1081 & 25.2 (23.3 to 27.1$)$ & & 351 & 8.3 (7.4 to 9.4$)$ & \\
\hline Current smoker (>10) & 711 & 44.4 (40.9 to 47.9$)$ & & 369 & $24.8(22.2$ to 27.4$)$ & & 382 & $24.3(21.7$ to 27.0$)$ & & 158 & $10.5(9.2$ to 11.9$)$ & \\
\hline \multicolumn{13}{|l|}{ Alcohol intake** } \\
\hline Frequency & & & 0.118 & & & 0.136 & & & 0.830 & & & 0.044 \\
\hline None & 363 & 41.0 (36.5 to 45.7 ) & & 166 & 23.3 (19.1 to 28.0$)$ & & 193 & 24.7 (21.2 to 28.5 ) & & 84 & 11.5 (9.0 to 14.7$)$ & \\
\hline Low/moderate & 1383 & 36.7 (34.1 to 39.5 ) & & 649 & 18.7 (16.9 to 20.7$)$ & & 824 & 23.9 (21.9 to 26.0$)$ & & 273 & 7.8 (6.8 to 8.9$)$ & \\
\hline Excessive & 179 & 40.1 (33.4 to 47.3 ) & & 90 & 20.2 (16.3 to 24.8$)$ & & 108 & $25.0(20.5$ to 30.1$)$ & & 42 & 10.0 (6.9 to 14.3$)$ & \\
\hline $\begin{array}{l}\text { Binge drinking (days in preceding year consumed } \\
\text { five or more alcoholic drinks in a single day) }\end{array}$ & & & 0.382 & & & 0.075 & & & 0.701 & & & 0.742 \\
\hline None & 898 & 37.1 (34.5 to 39.7 ) & & 415 & 18.7 (16.7 to 20.8 ) & & 533 & 23.7 (21.6 to 26.0 ) & & 175 & $7.8(6.9$ to 8.9$)$ & \\
\hline$\leq 12$ days & 347 & 35.6 (31.6 to 39.8 ) & & 167 & 17.9 (14.7 to 21.5$)$ & & 226 & 25.1 (21.8 to 28.8 ) & & 77 & 8.1 (6.1 to 10.7$)$ & \\
\hline$>12$ days & 315 & 39.2 (34.9 to 43.7 ) & & 158 & 20.8 (17.5 to 24.6$)$ & & 174 & 23.6 (20.3 to 27.2$)$ & & 64 & $8.7(6.5$ to 11.5$)$ & \\
\hline Caffeine intake (daily average, mg) & & & 0.372 & & & 0.052 & & & 0.463 & & & 0.126 \\
\hline $0-29.5$ & 476 & 33.0 (28.5 to 37.9$)$ & & 214 & 16.0 (12.6 to 20.1$)$ & & 334 & 26.6 (22.5 to 31.1$)$ & & 90 & $7.0(4.7$ to 10.5$)$ & \\
\hline $29.6-97.0$ & 516 & 36.7 (32.2 to 41.5$)$ & & 237 & 18.1 (15.3 to 21.2 ) & & 315 & 22.9 (19.2 to 27.2$)$ & & 115 & 7.4 (5.8 to 9.4$)$ & \\
\hline $97.1-208.5$ & 515 & 37.3 (33.7 to 41.1$)$ & & 239 & 20.5 (17.4 to 24.0$)$ & & 312 & 25.3 (22.1 to 28.8 ) & & 117 & $9.9(7.9$ to 12.4$)$ & \\
\hline$>208.5$ & 538 & 37.7 (33.8 to 41.8$)$ & & 268 & 21.7 (18.2 to 25.6$)$ & & 306 & 22.8 (19.9 to 25.8$)$ & & 121 & $9.8(7.4$ to 12.9$)$ & \\
\hline \multicolumn{13}{|l|}{ Job characteristics } \\
\hline Hours worked in all jobs in preceding week & & & 0.001 & & & 0.006 & & & 0.336 & & & 0.035 \\
\hline$<48$ & 1637 & 34.4 (32.0 to 37.0 ) & & 781 & $18.4(17.0$ to 19.9$)$ & & 1061 & 24.4 (22.7 to 26.2 ) & & 350 & $8.2(7.3$ to 9.2$)$ & \\
\hline$\geq 48$ & 792 & 46.1 (42.2 to 50.1$)$ & & 337 & 21.4 (18.5 to 24.6$)$ & & 417 & 25.9 (23.0 to 29.0$)$ & & 164 & 10.5 (8.7 to 12.5$)$ & \\
\hline Years worked in current/main job & & & 0.153 & & & 0.804 & & & 0.017 & & & 0.562 \\
\hline$<10$ & 1820 & 37.0 (34.7 to 39.3 ) & & 883 & 19.3 (17.6 to 21.0$)$ & & 1209 & $26.0(24.1$ to 28.0$)$ & & 413 & $8.6(7.6$ to 9.7$)$ & \\
\hline$\geq 10$ & 691 & 39.0 (35.7 to 42.5 ) & & 280 & 19.0 (16.1 to 22.3 ) & & 336 & 21.7 (19.0 to 24.6$)$ & & 124 & $9.3(7.4$ to 11.7$)$ & \\
\hline Occupation categories & & & 0.001 & & & 0.044 & & & 0.003 & & & 0.593 \\
\hline White collar & 1167 & 34.1 (31.5 to 36.8 ) & & 586 & 18.9 (16.7 to 21.2$)$ & & 817 & 25.9 (23.9 to 27.9$)$ & & 273 & $8.5(7.4$ to 9.9$)$ & \\
\hline Service & 554 & $36.0(32.1$ to 40.1$)$ & & 278 & 20.3 (17.9 to 22.9$)$ & & 361 & 26.2 (22.7 to 30.1$)$ & & 135 & $10.0(8.0$ to 12.3$)$ & \\
\hline Farm and blue collar & 786 & 46.2 (42.3 to 50.2$)$ & & 299 & 19.2 (16.6 to 22.2 ) & & 366 & 21.5 (19.1 to 24.0$)$ & & 129 & 8.6 (7.0 to 10.6$)$ & \\
\hline \multicolumn{13}{|l|}{ Sleep characteristics } \\
\hline Physician-diagnosed sleep disorder†† & & & 0.005 & & & 0.001 & & & 0.001 & & & 0.001 \\
\hline No & 2335 & 37.0 (34.8 to 39.4 ) & & 1016 & 17.7 (16.1 to 19.3$)$ & & 1396 & 23.9 (22.2 to 25.8$)$ & & 454 & $8.0(7.1$ to 9.0$)$ & \\
\hline Yes & 174 & 46.1 (39.5 to 52.7 ) & & 144 & 41.6 (36.0 to 47.5$)$ & & 146 & 36.9 (31.4 to 42.8$)$ & & 82 & 20.9 (15.5 to 27.5$)$ & \\
\hline $\begin{array}{l}\text { Sleeping pills or other medication use } \\
\text { to help with sleep (times in preceding month) }\end{array}$ & & & 0.189 & & & 0.001 & & & 0.001 & & & 0.001 \\
\hline$<5$ & 2361 & 37.3 (35.1 to 39.6 ) & & 1010 & 17.2 (15.8 to 18.7$)$ & & 1408 & 23.6 (21.9 to 25.2$)$ & & 463 & $7.8(7.0$ to 8.7$)$ & \\
\hline$\geq 5$ & 151 & 41.5 (34.7 to 48.7$)$ & & 153 & $48.6(43.3$ to 54.0$)$ & & 136 & $42.4(37.1$ to 47.9$)$ & & 74 & $23.0(18.5$ to 28.4$)$ & \\
\hline
\end{tabular}

*Sleep duration $<7$ hours per week/work day.

tParticipants categorised as having poor sleep quality if the response to any of the six sleep problem items was $16-30$ times/month

Participants with ADL score? (sample mean).

§Participants with poor sleep quality and poor ADL score.

IUnweighted sample size.

* Self-reported alcohol intake for the 12 months that preceded interview was determined for participants aged $\geq 20$ years. Alcohol intake was categorised as: excessive ( $>2$ drinks per day for men and $>1$ drink per day for women), low/moderate ( $>0$ but $<2$ drinks per day for men and $\leq 1$ drink per day for women) and none.

they had a sleep disorder, including sleep apnoea, insomnia, restless leg syndrome or 'other'.

ADL, activities of daily living; NHANES, National Health and Nutrition Examination Survey; PHQ-9, Patient Health Questionnaire-9; PIR, poverty income ratio. 
Table 4 PRs $(95 \% \mathrm{Cl})$ for sleep duration, quality, ADL score and insomnia in relation to regular shiftwork status among US workers (NHANES, 2005-2008)*

\begin{tabular}{|c|c|c|c|c|c|}
\hline \multirow[b]{2}{*}{ Outcome/model } & \multicolumn{5}{|c|}{ Regular shiftwork status } \\
\hline & Daytime shift & Night shift & Rotating shift & Evening shift & Another schedulet \\
\hline \multicolumn{6}{|l|}{ Sleep duration } \\
\hline \multicolumn{6}{|c|}{$<7$ vs $\geq 7$ hours per work or week night } \\
\hline Unadjusted & Ref. & 1.72 (1.52 to 1.94$)$ & 1.15 (0.99 to 1.33$)$ & 1.09 (0.93 to 1.27$)$ & $1.03(0.91$ to 1.17$)$ \\
\hline Model 1‡ & Ref. & 1.70 (1.50 to 1.93$)$ & 1.15 (0.99 to 1.34$)$ & $1.10(0.95$ to 1.27$)$ & $1.03(0.90$ to 1.17$)$ \\
\hline Model $2 \S$ & Ref. & 1.70 (1.48 to 1.96$)$ & $1.14(0.96$ to 1.35$)$ & $1.06(0.91$ to 1.24$)$ & $1.06(0.94$ to 1.21$)$ \\
\hline \multicolumn{6}{|c|}{ Sleep quality index } \\
\hline \multicolumn{6}{|c|}{ Poor quality } \\
\hline Unadjusted & Ref. & 1.67 (1.37 to 2.03$)$ & $1.05(0.80$ to 1.36$)$ & 1.25 (0.95 to 1.66$)$ & 1.01 (0.81 to 1.27$)$ \\
\hline Model 1‡ & Ref. & $1.70(1.40$ to 2.05$)$ & $1.05(0.80$ to 1.37$)$ & $1.25(0.94$ to 1.65$)$ & 1.03 (0.83 to 1.28$)$ \\
\hline Model $2^{* *}$ & Ref. & 1.52 (1.24 to 1.85$)$ & $1.07(0.82$ to 1.39$)$ & $1.12(0.82$ to 1.52$)$ & $1.06(0.85$ to 1.32$)$ \\
\hline \multicolumn{6}{|c|}{ Moderate quality } \\
\hline Unadjusted & Ref. & $0.85(0.65$ to 1.10$)$ & $1.14(0.92$ to 1.42$)$ & $1.10(0.90$ to 1.33$)$ & 1.29 (1.10 to 1.52$)$ \\
\hline Model $1 \ddagger$ & Ref. & 0.84 (0.65 to 1.08$)$ & 1.09 (0.88 to 1.34$)$ & $1.04(0.86$ to 1.27$)$ & 1.29 (1.10 to 1.50$)$ \\
\hline Model 2** & Ref. & $0.86(0.63$ to 1.19$)$ & $1.07(0.86$ to 1.33$)$ & $1.08(0.88$ to 1.32$)$ & 1.25 (1.06 to 1.47$)$ \\
\hline \multicolumn{6}{|c|}{ Sleep-related ADL score†† } \\
\hline \multicolumn{6}{|c|}{$\geq 2$ vs $<2$} \\
\hline Unadjusted & Ref. & 1.53 (1.24 to 1.89$)$ & $0.99(0.81$ to 1.21$)$ & 1.23 (1.01 to 1.50$)$ & $1.17(0.96$ to 1.41$)$ \\
\hline Model 1‡ & Ref. & $1.49(1.20$ to 1.85$)$ & $0.94(0.77$ to 1.14$)$ & $1.15(0.96$ to 1.40$)$ & $1.19(0.98$ to 1.45$)$ \\
\hline Model 2‡¥ & Ref. & 1.39 (1.11 to 1.73$)$ & $0.98(0.82$ to 1.18$)$ & $1.11(0.91$ to 1.36$)$ & $1.19(0.99$ to 1.43$)$ \\
\hline \multicolumn{6}{|l|}{ Insomnia } \\
\hline Unadjusted & Ref. & 2.19 (1.58 to 3.03$)$ & $1.11(0.73$ to 1.68$)$ & $1.15(0.82$ to 1.61$)$ & $0.83(0.57$ to 1.22$)$ \\
\hline Model $1 \ddagger$ & Ref. & $2.19(1.59$ to 3.02$)$ & $1.08(0.71$ to 1.65$)$ & $1.11(0.81$ to 1.53$)$ & $0.86(0.58$ to 1.25$)$ \\
\hline Model $2 \S \S$ & Ref. & $2.03(1.30$ to 3.17$)$ & 1.11 (0.65 to 1.88$)$ & 0.92 (0.59 to 1.42$)$ & 0.88 (0.58 to 1.34$)$ \\
\hline \multicolumn{6}{|c|}{ 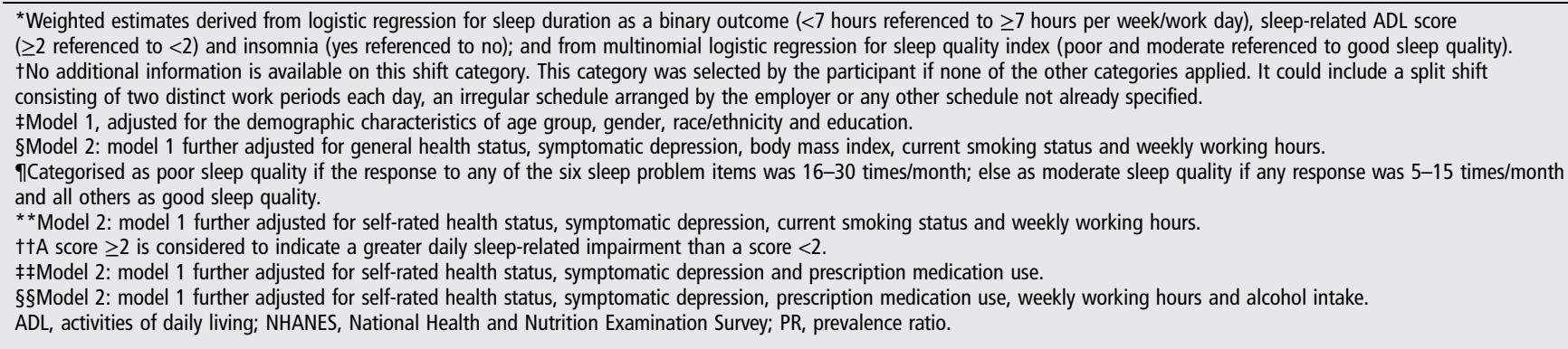 } \\
\hline
\end{tabular}

\section{Recommendations}

Although night shift is associated with all of the sleep problems we investigated, some workers are better able to tolerate night shifts, as demonstrated by the fact that not all night shift workers had sleep problems. These higher tolerant workers may be more receptive to the advantages to night shiftwork which include: commuting when roads are less crowded, higher wages to compensate for the inconvenience of night shift, enjoying public places that are often less crowded when they are off work and having greater independence since fewer supervisors may be present on night shifts.

Given the likely growth in the demands from globalisation and societies' need for services around the clock, work-based prevention programmes and policies should be adopted to improve the quantity and quality of sleep among workers. Unfortunately, there is no single ideal strategy to successfully address the sleep risks of every demanding shiftwork situation. Instead, interventions often need to be customised to the specific employer and worker. ${ }^{40}$ These include designing new shift schedules with frequent rest breaks, avoiding night shifts that exceed 8 hours, improving the sleep environment (eg, blocking sunlight and sound from the bedroom, and keeping the bedroom cool), taking a long nap before the night shift begins (eg, from 19:30 to 22:00), accelerating the modulation of circadian rhythms using bright lights, improving physical fitness, engaging in stress reduction activities, and strengthening family and social support.

Correction notice This paper has been updated since it first published online. Tables 2,3 and 4 have been reformatted to make them clearer to the reader.

Twitter Follow Geoffrey Calvert at @gmcalvert1

Competing interests None declared.

Patient consent Obtained.

Ethics approval NCHS Research Ethics Review Board.

Provenance and peer review Not commissioned; externally peer reviewed.

\section{REFERENCES}

1 Institute of Medicine. Sleep disorders and sleep deprivation: an unmet public health problem. Washington (DC): National Academies Press, 2006.

2 Cappuccio FP, D'Elia L, Strazzullo P, et al. Sleep duration and all-cause mortality: a systematic review and meta-analysis of prospective studies. Sleep 2010;33:585-92.

3 Chandola T, Ferrie JE, Perski A, et al. The effect of short sleep duration on coronary heart disease risk is greatest among those with sleep disturbance: a prospective study from the Whitehall II cohort. Sleep 2010;33:739-44.

4 Vgontzas AN, Liao D, Pejovic S, et al. Insomnia with short sleep duration and mortality: the Penn State cohort. Sleep 2010;33:1159-64. 
5 Kessler RC, Berglund PA, Coulouvrat C, et al. Insomnia and the performance of US workers: results from the America Insomnia Survey. Sleep 2011;34:1161-71.

6 Lombardi DA, Folkard S, Willetts JL, et al. Daily sleep, weekly working hours, and risk of work-related injury: US National Health Interview Survey (2004-2008). Chronobiol Int 2010;27:1013-30.

7 Williamson A, Lombardi DA, Folkard $\mathrm{S}$, et al. The link between fatigue and safety. Accid Anal Prev 2011;43:498-515.

8 Hossain JL, Shapiro CM. The prevalence, cost implications, and management of sleep disorders: an overview. Sleep Breath 2002;6:85-102.

9 National Sleep Foundation. 2009 Sleep in America Poll. http://healthyliving. free-domblogging.com/files/2009/03/2009sleeppoll.pdf

10 Akerstedt $\mathrm{T}$, Ingre $\mathrm{M}$, Broman JE, et al. Disturbed sleep in shift workers, day workers, and insomniacs. Chronobiol Int 2008;25:333-48.

11 Drake CL, Roehrs T, Richardson G, et al. Shift work sleep disorder: prevalence and consequences beyond that of symptomatic day workers. Sleep 2004;27:1453-62.

12 Ohayon MM, Lemoine $\mathrm{P}$, Arnaud-Briant V, et al. Prevalence and consequences of sleep disorders in a shift worker population. J Psychosom Res 2002;53:577-83.

13 Ohayon MM, Smolensky MH, Roth T. Consequences of shift working on sleep duration, sleepiness and sleep attacks. Chronobiol Int 2010;27:575-89.

14 Luckhaupt SE, Tak SW, Calvert GM. The prevalence of short sleep duration by industry and occupation in The National Health Interview Survey. Sleep 2010;33:149-59.

15 Centers for Disease Control and Prevention. Short sleep duration among workersUnited States, 2010. MMWR Morb Mortal Wkly Rep 2012;61:281-5.

16 Quan SF, Howard BV, Iber C, et al. The Sleep Heart Health Study: design, rationale, and methods. Sleep 1997:20:1077-85.

17 Hirshkowitz M, Whiton K, Albert SM, et al. National Sleep Foundation's sleep time duration recommendations: methodology and results summary. Sleep Health 2015;1:40-3.

18 Bansil P, Kuklina EV, Merritt RK, et al. Associations between sleep disorders, sleep duration, quality of sleep, and hypertension: results from The National Health and Nutrition Examination Survey, 2005 to 2008. J Clin Hypertens 2011;13:739-43.

19 Chasens ER, Ratcliffe SJ, Weaver TE. Development of the FOSQ-10: a short version of the Functional Outcomes of Sleep Questionnaire. Sleep 2009;32:915-19.

20 Plantinga L, Lee $\mathrm{K}$, Inker LA, et al. Association of sleep-related problems with CKD in the United States, 2005-2008. Am J Kidney Dis 2011;58:554-64.

21 American Psychiatric Association. Diagnostic and statistical manual of mental disorders. 5th edn. Washington (DC): American Psychiatric Association, 2013:361-8.

22 Harper S, Lynch J. Trends in socioeconomic inequalities in adult health behaviors among US states, 1990-2004. Public Health Rep 2007;122:177-89.

23 Kroenke K, Spitzer RL, Williams JB. The PHQ-9: validity of a brief depression severity measure. J Gen Intern Med 2001;16:606-13.

24 Johnson CL, Paulose-Ram R, Ogden CL, et al. National health and nutrition examination survey: analytic guidelines, 1999-2010. Vital Health Stat 2 2013:1-24.
25 Raaijmakers QAW. Effectiveness of different missing data treatments in surveys with Likert-type data: introducing the relative mean substitution approach. Educ Psychol Meas 1999;9:725-48.

26 Fransen M, Wilsmore B, Winstanley J, et al. Shift work and work injury in the New Zealand Blood Donors' Health Study. Occup Environ Med 2006;63:352-8.

27 Sack RL, Auckley D, Auger RR, et al. Circadian rhythm sleep disorders: part I, basic principles, shift work and jet lag disorders. An American Academy of Sleep Medicine review. Sleep 2007:30:1460-83.

28 Monk TH, Buysse DJ, Billy BD, et al. Shiftworkers report worse sleep than day workers, even in retirement. J Sleep Res 2013;22:201-8.

29 Tucker P, Folkard S, Ansiau D, et al. The effects of age and shiftwork on perceived sleep problems: results from the VISAT combined longitudinal and cross-sectional study. J Occup Environ Med 2011;53:794-8.

30 Ota A, Masue T, Yasuda N, et al. Association between psychosocial job characteristics and insomnia: an investigation using two relevant job stress models -the demand-control-support (DCS) model and the effort-reward imbalance (ERI) model. Sleep Med 2005:6:353-8.

31 Centers for Disease Control and Prevention. Effect of short sleep duration on daily activities-United States, 2005-2008. MMWR Morb Mortal Wkly Rep 2011;60: 239-42.

32 Gildner TE, Liebert MA, Kowal P, et al. Associations between sleep duration, sleep quality, and cognitive test performance among older adults for six middle income countries: results from the Study on Global Aging and Adult Health (SAGE). J Clin Sleep Med 2014;10:613-21.

33 Dembe $A E$, Erickson JB, Delbos RG, et al. Nonstandard shift schedules and the risk of job-related injuries. Scand J Work Environ Health 2006;32:232-40.

34 Goel N, Rao H, Durmer JS, et al. Neurocognitive consequences of sleep deprivation. Semin Neurol 2009;29:320-39.

35 Frost $\mathrm{P}$, Kolstad HA, Bonde JP. Shift work and the risk of ischemic heart disease-a systematic review of the epidemiologic evidence. Scand I Work Environ Health 2009;5:163-79.

36 Krueger PM, Friedman EM. Sleep duration in the United States: a cross-sectional population-based study. Am J Epidemiol 2009;69:1052-63.

37 Lauderdale DS, Knutson KL, Yan LL, et al. Objectively measured sleep characteristics among early-middle-aged adults: the CARDIA study. Am J Epidemiol 2007; 164:5-16

38 Morgenthaler T, Alessi C, Friedman L, et al. Practice parameters for the use of actigraphy in the assessment of sleep and sleep disorders: an update for 2007. Sleep 2007;30:519-29.

39 Saksvik IB, Bjorvatn $B$, Hetland $H$, et al. Individual differences in tolerance to shift work-a systematic review. Sleep Med Rev 2011;15:221-35.

40 Caruso CC, Rosa RR. Chapter 90. Shift work and long work hours. In: Rom WN, ed. Environmental and occupational medicine. 4th edn. Philadelphia: Lippincott Williams \& Wilkins, 2007:1359-63. 